\begin{tabular}{|c|c|c|c|c|c|c|}
\hline \multirow{4}{*}{ Impact Factor: } & ISRA (India) & $=3.117$ & SIS (USA) & $=0.912$ & ICV (Poland) & $=6.630$ \\
\hline & ISI (Dubai, UAE & $=0.829$ & РИНЦ (Russia) & $=0.156$ & PIF (India) & $=1.940$ \\
\hline & GIF (Australia) & $=0.564$ & ESJI (KZ) & $=8.716$ & IBI (India) & $=4.260$ \\
\hline & JIF & $=1.500$ & SJIF (Morocco) & $=5.667$ & OAJI (USA) & $=0.350$ \\
\hline
\end{tabular}

\section{SOI: 1.1/TAS DOI: 10.15863/TAS International Scientific Journal Theoretical \& Applied Science}

p-ISSN: 2308-4944 (print) e-ISSN: 2409-0085 (online)

Year: $2019 \quad$ Issue: $05 \quad$ Volume: 73

Published: $30.05 .2019 \quad$ http://T-Science.org
QR - Issue

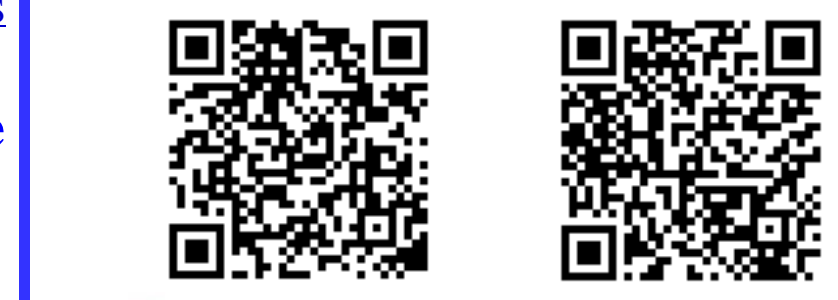

QR - Article

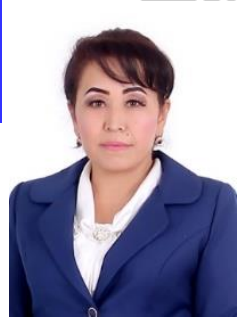

Khilola Yakubjanovna Najmiddinova Associate Professor Namgu (Uzbekistan). xilola1304@mail.ru.

\title{
ORGANIZATION INTENSIVE MATHEMATICAL TRAINING WITH THE HELP OF COMPUTER GAMES IN THE PRESCHOOL EDUCATION SYSTEM
}

Abstract: This article discusses how to use intensive math education in preschool children, using intelligent mathematical computer games and purposefully developed program "Parental Control".

Key words: game, game activity, computer games, stages of game, program of computer game, math games, program "Parental control", examples with "windows", addition and subtraction within 100, intensive mathematical training.

Language: Russian

Citation: Najmiddinova, K. Y. (2019). Organization intensive mathematical training with the help of computer games in the preschool education system. ISJ Theoretical \& Applied Science, 05 (73), 523-526.

Soi: http://s-o-i.org/1.1/TAS-05-73-79 Doi: crossef https://dx.doi.org/10.15863/TAS.2019.05.73.79

\section{ОРГАНИЗАЦИЯ ИНТЕНСИВНОЕ МАТЕМАТИЧЕСКОЕ ОБУЧЕНИЕ С ПОМОЩЬЮ КОМПЬЮТЕРНЫХ ИГР В СИСТЕМЕ ДОШКОЛЬНОГО ОБРАЗОВАНИЯ}

Аннотация: В этой статье обсуждается способы применений интенсивную математическую образованию $y$ детей дошкольного возраста, $c$ помощью интеллектуальных математических компьютерных игр и целенаправленно разработанной программы «Родительский контроль».

Ключевые слова: игра, игровая деятельность, компьютерные игры, этапь игры, программа компьютерной игры, математические игры, программа «Родительский контроль», примеры с «окошками», сложение и вычитание в пределах 100, интенсивное математическое обучение.

\section{Introduction}

«Игра - это огромное светлое окно, через которое в духовный мир ребенка вливается живительный поток представлений, понятий об окружаюшем мире. Игра - это искра, зажигающия огонек пытливости и любознательности».

В. А. Сухомлинский [1].

Детство - это особый мир, который сохраняется в душе человека на всю жизнь, если в нем царят счастье и радость быть самим собой. Мир фантазии, выдумки у детей связан с игрой. Во все исторические времена дети разных народов играли и играют, подражая взрослым, реализуя свои желания и творческие потребности. Игра - это самое важное, интересное и значимое для ребенка. Это и радость, и познание, и творчество. Игровая деятельность является ведущей для дошкольника. Умение играть ребенок приобретает в процессе своего развития. Правильно развивающийся ребенок - это, без сомнения, играющий ребенок. Игра определенное отношение мира к ребенку и ребенка к миру, ребенка к взрослому и взрослого к ребенку, ребенка к сверстнику, сверстника к нему [8]. Взрослые всегда стараются окружить своего малыша любовью, заботой, вниманием, лаской. Они стараются научить его радоваться жизни, доброжелательно относиться к окружающим.

Именно игровая роль в концентрированной форме воплощает связь ребенка с обществом. 


\begin{tabular}{|c|c|c|c|c|c|c|}
\hline \multirow{4}{*}{ Impact Factor: } & ISRA (India) & $=3.117$ & SIS (USA) & $=0.912$ & ICV (Poland) & $=6.630$ \\
\hline & ISI (Dubai, UAE & $=0.829$ & РИНЦ (Russia & $=0.156$ & PIF (India) & $=1.940$ \\
\hline & GIF (Australia) & $=0.564$ & ESJI (KZ) & $=8.716$ & IBI (India) & $=4.260$ \\
\hline & JIF & $=1.500$ & SJIF (Morocce & $=5.667$ & OAJI (USA) & $=0.350$ \\
\hline
\end{tabular}

Таким образом, чтобы понять внутренний мир ребенка, нужно изучить язык игры. В игре дети «говорят» с помощью игрушек, игровых действий, сюжета, ролей. Играя, ребенок легче устанавливает связь с миром взрослых и с миром вообще, у него появляются навыки внутреннего диалога, необходимого для продуктивного мышления.

Компьютерная игра - новый вид развивающего обучения. Компьютерная игра для ребенка почти всегда удовольствие, он играет с увлечением и воспринимает игру как отдых [2]. Именно этот факт делает компьютерные игры незаменимым наставником, воспитывающим и образовывающим ребенка, без лишних нравоучений не вызывая протеста или скуки. А значит, навыки и взгляды, которые возникли благодаря игре, останутся в активной памяти надолго.

\section{Materials and Methods}

В условиях современного развития общества и производства невозможно себе представить мир без информационных ресурсов, не менее значимых, чем материальные, энергетические и трудовые. Компьютеризация, постепенно проникающая практически во все сферы жизни и деятельности современного человека, вносит свои коррективы и подходы к воспитанию и образованию детей дошкольного возраста. Отечественные и зарубежные исследования по использованию компьютера в детских садах убедительно доказывают не только возможность и целесообразность этого, но и особую роль компьютера в развитии интеллекта и в целом личности ребенка. Занятия с применением компьютерных игр очень интересны дошкольникам. Они с большим удовольствием осваивают программы, добиваясь их правильного решения. В игре ребенок оперирует своими знаниями, опытом, впечатлением, отображенными в общественной форме игровых способов действия, игровых знаков, приобретающих значение в смысловом поле игр. Именно эта способность является главнейшей психологической базой для введения в игру дошкольника - компьютера, как игрового средства.

Компьютерные игры для дошкольников должны быть увлекательными, развивать внимание, быстроту реакций, тренировать память. Выполнение всех игровых заданий должно обучить ребенка аналитически мыслить в нестандартных ситуациях, классифицировать и обобщать понятия; развивать мелкую моторику рук и зрительно-моторную координацию. Кроме того, игра должна быть осмысленной и простой одновременно, без агрессии.
По сравнению с традиционными формами обучения дошкольников компьютер дает рядом преимуществ:

- предъявление информации на экране компьютера в игровой форме вызывает у детей огромный интерес;

- несет себе образный тип информации, понятный дошкольникам;

- движения, звук, мультипликация надолго привлекает внимание ребенка;

- проблемные задачи, поощрение ребенка при их правильном решении самим компьютером являются стимулом познавательной активности детей;

- предоставляет

возможность индивидуализации обучения;

- ребенок сам регулирует темп и количество решаемых игровых обучающих задач;

- в процессе своей деятельности за компьютером дошкольник приобретает уверенность в себе, в том, что он многое может;

- позволяет моделировать такие жизненные ситуации, которые нельзя увидеть в повседневной жизни;

- компьютер очень «терпелив», никогда не ругает ребенка за ошибки, а ждет, пока он сам исправит их.

Как известно, огромную роль в умственном воспитании и в развитии интеллекта играет математика. В настоящее время, в эпоху компьютерной революции встречающаяся точка зрения, выражаемая словами: "Не каждый будет математиком”, безнадежно устарела. Сегодня, а тем более, завтра математика будет необходима огромному числу людей различных профессий.

Математика всегда считалась одним из самых трудных предметов. Математика позволяет развить умственные качества, улучшает возможности абстрактного мышления, способность концентрироваться, тренирует память и усиливает быстроту мышления, развивает его пластичность.

Изучение математики младшими школьниками открывает широкие возможности для развития их творческого мышления. Обучение счету, выполнению арифметических действий и решению задач остается главной задачей начального обучения. Однако когда-то эта задача была единственной, в настоящее же время она становится лишь важной составной частью более обширной и разнообразной подготовки детей к изучению математики. Обучение должно обеспечивать подготовку мышления детей к овладению способами рассуждений, применяемыми в математике, и готовить их к усвоению важнейших математических понятий, таких, как число, геометрическая фигура, функция, величина т.д. 


\begin{tabular}{|c|c|c|c|c|c|c|}
\hline \multirow{4}{*}{ Impact Factor: } & ISRA (India) & $=3.117$ & SIS (USA) & $=0.912$ & ICV (Poland) & $=6.630$ \\
\hline & ISI (Dubai, UAI & $=0.829$ & РИНЦ (Russia & $=0.156$ & PIF (India) & $=1.940$ \\
\hline & GIF (Australia) & $=0.564$ & ESJI (KZ) & $=8.716$ & IBI (India) & $=4.260$ \\
\hline & JIF & $=1.500$ & SJIF (Morocco & $=5.667$ & OAJI (USA) & $=0.350$ \\
\hline
\end{tabular}

Каждый родитель желает своему ребенку, чтобы вырос умным, хорошо развитым и проявлял заинтересованность к учебе. Тем не менее, существует сложность в проявлении интереса у малыша в получении новых знаний. Одним их первых проявлений интереса к знаниям у детей дошкольного возраста является счет.

Чтобы научить считать в уме, отметим, что обучение следует начинать планомерно, при достижении ребенком возраста 3-х, 4-х лет. Процесс должен быть игровым. В противном случае, у малыша можно заблокировать желание учиться [8].

Умственный процесс, касающийся счета всегда начинается с простых действий. Как правило, они подразделены на два компонента речевой и двигательный [9].

1. Речевое действие развивается по схеме сначала говорим о том, что делаем, затем шепчем, а после счет происходит про себя. И лишь после этого этапа можно переходит на быстрый счет. К примеру, при сложении единиц $1+1$, называется следующая цифра в ряду, т.е. в уме ребенок сразу будет добавлять $1,2,3,4 \ldots$

2. Двигательный элемент развивается с обычного перекладывания предметов из стороны в сторону. Таким образом, в игровой форме предметы будут увеличиваться или уменьшаться. Поначалу ребенок будет следить за счетом пальчиком, затем только глазами, в уме совершая математические действия.

Развитие каждого человека происходит индивидуально. Совершение ошибок в процессе ознакомления с материалом - нормально. Тем не менее, многие родители не понимают, отчего смышленый ребенок не способен понять простых вещей, с точки зрения взрослого.

Отметим, что мозг ребенка отличен по своей структуре от мозга взрослого человека. Малыши не хотят и не могут запоминать то, что не вызывает их интереса [10].

Память у детей устроена таким образом, что она хранит только то, что вызывает эмоциональный ответ [10]. При этом не имеет значение позитивные это эмоции, или негативные.

Обучить ребенку счету достаточно непросто, при этом все родители стремятся, чтобы он делал не задумываясь. Ежедневные упражнения, увлекательные формы занятий вкупе с нашим упорством и терпеливостью помогут ребенку освоить королеву наук - математику.

Поскольку ведущая деятельность у малышей - игра, тем более, в настоящее время, компьютерная игра, то и обучаться проще всего в процессе игры, компьютерные игры.

С этой целью, мы разработали программы, как «Автоолам» [3], «Кувнок шакллар» [4], «Интеллектуал карточкалар» [5], «Сонга тулдир»
[6] и «Ота-она назорати» [7]. Программы этих компьютерных игр прикреплены с программой «Ота-она назорати». Программа «Ота-она назорати» «заставляет» ребенку играть этих математических игр, которые представлены программой постепенно на блокировке экрана. Когда ребенок достигнет текущего успеха, т.е. успешно заканчивает текущей этап игры, блокировка экрана открывается на время, и он может общаться с компьютером (играть в игры, смотреть мультфильмы или кино, разрешенные родителями и т.п.). Этапы игры составлены от простого к сложному.

Bce сведения, необходимые для статистической обработки результата игры сохраняются на память компьютера в виде протокола (рис. 2).

Проведен полный эксперимент по каждой игре с несколькими детьми 4-6 лет и сделаны статистические обработки. Например, продолжительность игры «Интеллектуал карточкалар» была 3-3,5 месяца. Программа этой игры предлагает ребенку примеры с “окошками” по сложению и вычитанию в пределах 100 (рис.1). Когда ребенок решает 10 примеры правильно, тогда считается, что он закончил текущий этап с успехом (т.е. блокировка экрана открывается). Было известно, что дети решили около 250-300 примеров в день (представьте себе, настолько стимулирующий подход необходимо в традиционной методике!). Дети добились успеха при решении примеров вида $a+b=x, a-b=x, a-x=c$ в среднем 88 $89 \%$, примеров вида $a+x=c$ и $x+b=c$ в среднем 85 - $86 \%$. Кроме того, определено, что дети решили большинство задач только за 1-2 секунды. Но для детей затруднительно были примеры вида $x-b=c$, поэтому они решили такие задачи в среднем на $55-56 \%$.

\section{Conclusion}

Таким образом, можно сделать вывод, что при разумном подходе и соблюдении необходимых условий, компьютерные игры являются эффективным средством интенсивно формирования предметных знаний и умений, а также социально-значимых личностных качеств детей дошкольного возраста. При этом негативное влияние компьютера при грамотной организации процесса можно свести к минимуму. Основное же положительное значение компьютерных игр заключается в богатых, разнообразных условиях игровой деятельности, которые позволяют достичь образовательных целей наиболее эффективным и привлекательным для детей способом. 


\begin{tabular}{|c|c|c|c|c|c|c|}
\hline \multirow{4}{*}{ Impact Factor: } & ISRA (India) & $=3.117$ & SIS (USA) & $=0.912$ & ICV (Poland) & $=6.630$ \\
\hline & ISI (Dubai, UAE & $=0.829$ & РИНЦ (Russia & $=0.156$ & PIF (India) & $=1.940$ \\
\hline & GIF (Australia) & $=0.564$ & ESJI (KZ) & $=8.716$ & IBI (India) & $=4.260$ \\
\hline & JIF & $=1.500$ & SJIF (Morocce & $=5.667$ & OAJI (USA) & $=0.350$ \\
\hline
\end{tabular}

\section{References:}

1. Sukhomlinskiy, V. A. (1974). Serdtse otdayu detyam. (p.33). Kiev: Radyans'ka shkola.

2. Vasenina, S. I. (2015). Razvivayushchie komp'yuternye igry kak sredstvo matematicheskogo razvitiya detey doshkol'nogo vozrasta. Molodoy uchenyy, № 20.1, pp. 8-10.

3. Badalov, M., Nazhmiddinova, K., \& Zhamolov, O. (2017). «Avtoolam» $\breve{Y}_{z R}$ Intellektual mulk Agentligi, guvokhnoma № DGU 04289, 10.03.2017.

4. Badalov, M., Nazhmiddinova, K., \& Makhmudaliev, G. (2017). "Kuvnok shakllar» $\breve{y}_{z}$ Intellektual mulk Agentligi, guvokhnoma № DGU 04288, 10.03.2017.

5. Badalov, M., Nazhmiddinova, K., Mirzamov, A., \& Bakhromova, M. (2017). "Intellektual kartochkalar» $\breve{Y}_{z} R$ Intellektual mulk Agentligi, guvokhnoma № DGU 04622, 09.08.2017.
6. Nazhmiddinova, K., \& Mirzamov, A. (2017). «Songa tuldir» $\breve{Y}_{z} R$ Intellektual mulk Agentligi, guvokhnoma № DGU 04620, 09.08.2017.

7. Mirzamov, A., \& Nazhmiddinova, K. (2017). "Ota-ona nazorati” dasturi $\breve{Y}_{z} R$ Intellektual mulk Agentligi, guvokhnoma № DGU 04482, 16.06.2017.

8. Perova, M. I. (1996). Didakticheskie igry $i$ uprazhneniya po matematike dlya raboty s det'mi doshkol'nogo i mladshego shkol'nogo vozrasta. Moscow: Prosveshchenie.

9. (n.d.). Retrieved 2019, from https://detstrana.ru/article/deti-3-7/razvitie/10uvlekatelnyh-sposobov-obuchit-rebyonkamatematike/

10. (n.d.). Nauka i zhizn', psikhologiya komp"yuternykh igr. Retrieved 2019, from https://www.nkj.ru/archive/articles/9696/ 